\title{
Depression and Leisure-Time Physical Activity in Pubertal Girls
}

\author{
Nora Nabil Hussien", Rasha Mohammed Bahaa Eldin \\ Department of Family Medicine-Faculty of Medicine, Zagazig University, Zagazig, Egypt \\ Email address: \\ dr.nora_jana@yahoo.com (N. N. Hussien), Rasha_bahaa@yahoo.com (R. M. B. Eldin) \\ ${ }^{*}$ Corresponding author
}

\section{To cite this article:}

Nora Nabil Hussien, Rasha Mohammed Bahaa Eldin. Depression and Leisure-Time Physical Activity in Pubertal Girls. Journal of Family Medicine and Health Care. Vol. 6, No. 4, 2020, pp. 106-112. doi: 10.11648/j.jfmhc.20200604.11

Received: October 10, 2020; Accepted: October 23, 2020; Published: November 4, 2020

\begin{abstract}
Treating depression can be a financial burden on the health care system and time consuming; finding an alternative that may prevent or decrease the occurrence of depression may be better for adolescents. This study intended to estimate the prevalence of depression among pubertal school adolescent girls and to determine the difference between physically active pubertal girls and sedentary ones regarding the presence of depressive symptoms. It is a cross sectional study, done in $10^{\text {th }}$ of Ramadan city, on 365 adolescent pubertal girls in 7-12 grades. The Short Moods and Feelings Questionnaire (SMFQ) was used to evaluate depressive symptoms and Godin Leisure-Time Exercise questionnaire for the assessment of self-reported leisure-time physical activity. This study revealed that the prevalence of depression in adolescent girls was (47.4\%). Depression is significantly present among insufficiently active students (53.8\%) with (COR 3.9, 95\% CI 2.4-6.5) with $(\mathrm{P}<0.001)$. The percent of active students are significantly higher among those attending private schools (44.4\%) (COR 3.7, 95\% CI 2.1-6.8) versus (27.4\%-28.2\%) (COR 1.2, 95\% CI 0.8-2.0 and 0.3, 95\% CI $0.2-0.5)$ respectively in language governmental and in governmental schools with ( $\mathrm{P}$ value $<0.001)$. There is significant negative correlation between depression and leisure-time physical activity $(\mathrm{r}=-0.49, \mathrm{P}<0.001)$. It was concluded that depression is inversely related to physical activity, so it's a must to encourage all adolescents to be engaged in regular bases physical activity to avoid psychiatric troubles as depression that may occur in this age with hormonal changes of puberty.
\end{abstract}

Keywords: Adolescents, Physical Activity, Depressive Symptoms

\section{Introduction}

Adolescence is a unique period of time (10-19 years). It is essential for developing and maintaining social and emotional habits important for mental well-being. These habits include: regular exercise, healthy sleep patterns, interpersonal skills, problem-solving and learning to manage their emotions. Promoting psychological wellbeing of adolescents and protecting them from bad experiences that may impact their potential to thrive is critical for their life and for their physical and mental health in adulthood [1].

The dramatic change in social behaviors is one of the distinctive features of adolescent development. They show higher self-consciousness, involve in complex peer relationships, experience sexual feelings and demonstrate more understanding of others compared to younger children. The emergence of these behaviors coincides with physical changes that occur during puberty, supporting the hypothesis that the social and behavioral changes of adolescence can result from pubertal hormone levels, via a direct influence on brain structure and function [2].

Several emotional disorders start during adolescence. Adolescents with emotional disorders can experience depression or anxiety, excessive irritability, frustration or anger. Symptoms can overlap across more than one emotional disorder with rapid and unexpected changes in mood and emotional outbursts [1]. Many factors can explain the proven rise in prevalence of depression after puberty with strong female preponderance (about 2:1); puberty, brain and cognitive maturation are the most commonly postulated contributors [3].

Participation in physical activity (PA) provides young 
people with multiple types of health benefits, including maintaining healthy weight, improving well-being, cardiovascular fitness, and bone health [4]. In addition to promoting health, PA improves cognitive performance and memory, higher energy levels [5], better mood and better sleep quality which are important during adolescence [6].

The aim of this study was to estimate the prevalence of depression among pubertal adolescents in 10th of Ramadan schools and to determine the difference between physically active pubertal girls and sedentary ones regarding the presence of depressive symptoms.

\section{Materials and Method}

\subsection{Study Design}

The study is a descriptive cross sectional study.

\subsection{Study Area}

Randomly selected schools from $10^{\text {th }}$ of Ramadan city.

\subsection{Study Population}

Adolescent pubertal girls on 7-12 grades. Students were excluded if they were diagnosed with any psychiatric problems and under treatment of any mental disorder (depression, anxiety, ADHD, etc) or having peer or family conflicts to avoid confounders.

\subsection{Sampling Technique and Sample Size}

Multistage random sampling technique: $1-10^{\text {th }}$ of Ramadan city was chosen randomly from the 17 city on El-Sharquia Governorate. The total number of schools in $10^{\text {th }}$ of Ramadan city is (133 schools) and they are divided into three types: governmental (55 primary, 42 preparatory and 16 secondary), language governmental (10) and private schools (10). The total number of adolescent girls in preparatory phase (5500 in governmental schools, 2800 in language governmental schools, 2900 in private schools) and secondary phase (2400 in governmental schools, 1100 in language governmental schools, 1200 in private schools) according to the $10^{\text {th }}$ of Ramadan directorate of education. 2- Schools included in the study were chosen randomly from each school type to include: (4 governmental schools, 2 language governmental schools and 2 private schools). 3- Then inside each school a random selection from secondary level classes and preparatory level classes are taken. 4- From each level, classes were chosen randomly from the 3 grades (grade 1, 2, 3) to represent each grade.

Students were interviewed first to avoid exclusion criteria, and then eligible students only were included: 238 students from selected preparatory level and 127 students from secondary level as the attendance level in secondary classes was week. All students from the chosen groups were invited to complete the two questionnaires during the academic year of 2019/2020.

The calculated sample size of this study was 365 students based on the estimated depression prevalence among female school students (15-17 years) in a previous study in Taif area, Kingdom of Saudi Arabia (KSA) (42.9\%) [7], measured by Open Epi, version 3 at $80 \%$ power of test and a confidence level of $95 \%$.

\subsection{Data Collection Tools}

All eligible students involved in this study were subjected to a questionnaire containing:

A- (Age, grade, school type).

B- Depressive symptoms were measured using the Short Moods and Feelings Questionnaire (SMFQ) [8]. It is a screening tool for depression used in primary care settings for 8-16 years old adolescents with (Sensitivity: 70\% \& Specificity: $85 \%$ ). It includes 13 statements about emotions and behavior over the past 2 weeks. The scores for the items were summed to produce an overall magnitude of symptoms, with a clinical cutoff 11 , higher score signifies depression.

C- Godin Leisure-Time Exercise questionnaire [9]. The questionnaire assesses the self-reported leisure-time physical activity. During a typical 7-Day period (a week), how many times on the average did the student involve in the following kinds of activities for more than 15 minutes during a free time. The leisure-time physical activity score is expressed in units and can be computed in two steps: 1- Weekly frequencies of strenuous (as running, jogging, hockey, football, soccer, squash, judo, vigorous swimming, basketball, vigorous long distance bicycling), moderate (e.g., fast walking, tennis, easy bicycling, volleyball, baseball, badminton, easy swimming, popular and folk dancing) and mild activities (e.g., yoga, golf, archery, fishing from river, bowling, easy walking) are multiplied by nine, five, and three, respectively; these values correspond to a value categories of the activities listed. 2- The total weekly leisure activity score is computed in arbitrary units by summing the products of the separate components, as shown in this formula:

\section{Weekly leisure-time activity score $=(9 \times$ Strenuous $)+(5 \times$ Moderate $)+(3 \times$ Mild $)$}

Godin Scale Score Interpretation: (24 units or more=Active), $(14-23$ units=Moderately Active), (Less than 14 units=Insufficiently Active/Sedentary)

\subsection{Data Management}

The collected data were entered and analyzed using SPSS package (version 16.0). Data was presented using frequencies The prevalence of depression among the studied students was assessed and the difference in presence of depression between groups regarding physical activity was compared by using Chi Square test, COR with 95\% CI. The correlation test was done between depression and leisure-time physical activity total scores. $\mathrm{P}$ values $\leq 0.05$ was used as an indicator of statistical significance. 


\subsection{Ethical Clearance}

Approval was obtained from Institutional Review Board (IRB) of faculty of medicine at Zagazig University (no 6457), the educational administration of $10^{\text {th }}$ of Ramadan city and from school administrators of the eight selected schools after thorough explanation of the study. Participation in the study was optional and the study aim was explained to all students and confidentiality was insured.

\section{Results}

The present study was done on 365 female students with an age range (11-18 years) and a mean age of (14.09 \pm 1.84 SD). Half of them were attending governmental schools and the other half were in language governmental and private schools. $65.2 \%$ in preparatory level and $34.8 \%$ in secondary level as seen in Table 1 .

Table 1. Distribution of students according to the type of school, level of education and grade ( $n=365)$.

\begin{tabular}{lll}
\hline Variable & No & \% \\
\hline Type of school & $(365)$ & \\
Private & 93 & 25.5 \\
Language governmental & 92 & 25.2 \\
Governmental & 180 & 49.3 \\
Preparatory level & $(238)$ & 65.2 \\
First grade & 62 & 17 \\
Second grade & 62 & 17 \\
Third grade & 114 & 13.2 \\
Secondary level & $(127)$ & 34.8 \\
First grade & 31 & 8.5 \\
Second grade & 30 & 8.2 \\
Third grade & 66 & 18.1 \\
\hline
\end{tabular}

Table 2 shows that only $34.0 \%$ of students were physically active, $27.4 \%$ were moderately active and $38.6 \%$ were sedentary.

Table 2. Distribution of students according to the degree of physical activity by Godin Leisure-Time Exercise questionnaire.

\begin{tabular}{lll}
\hline Physical activity state & No & \% \\
\hline Active & 124 & 34.0 \\
Moderately active & 100 & 27.4 \\
Insufficiently active (sedentary) & 141 & 38.6 \\
\hline
\end{tabular}

A secondary outcome presented in table 3: The percent of active students are significantly higher among those attending private school $(44.4 \%)$ versus $(27.4 \%-28.2 \%)$ respectively in language governmental and in governmental schools with ( $\mathrm{p}$ value $<0.001$ ). Also $76.6 \%$ of active students are among preparatory level versus $23.4 \%$ at secondary level with $(\mathrm{p}<0.003)$. Among preparatory level first grade students are more active $(48.4 \%)$ than second and third grade of the same level $\mathrm{p}<0.001$.

Table 3. The relation between physical activity and type of school, education level and grades.

\begin{tabular}{|c|c|c|c|c|c|c|}
\hline \multirow[b]{2}{*}{ Variable } & \multicolumn{3}{|c|}{ Physical activity } & \multirow{2}{*}{ Total (365) } & \multirow{2}{*}{$\chi^{2}$} & \multirow{2}{*}{$\mathbf{P}$} \\
\hline & Active (124) & Moderately active (100) & Insufficiently active (sedentary) (141) & & & \\
\hline Type of school & No $(\%)$ & No $(\%)$ & No $(\%)$ & No $(\%)$ & & \\
\hline Private & $55(44.4)$ & $21(21.0)$ & $17(12.1)$ & $93(25.5)$ & & \\
\hline Language governmental & $34(27.4)$ & $26(26.0)$ & $32(22.7)$ & $92(25.2)$ & 47.4 & $<0.001^{*}$ \\
\hline Governmental & $35(28.2)$ & $53(53.0)$ & $92(65.2)$ & $180(49.3)$ & & \\
\hline \multicolumn{7}{|l|}{ Education level } \\
\hline Preparatory & $95(76.6)$ & $63(63.0)$ & $80(56.7)$ & $238(65.2)$ & \multirow{2}{*}{11.8} & \multirow{2}{*}{$0.003 *$} \\
\hline Secondary & $29(23.4)$ & $37(37.0)$ & $61(43.3)$ & $127(34.8)$ & & \\
\hline Preparatory level & (95) No\% & (63) $\mathrm{No} \%$ & (80) No\% & (238) $\mathrm{No} \%$ & & \multirow{4}{*}{$<0.001^{*}$} \\
\hline First grade & $46(48.4)$ & $12(19.0)$ & $4(5.0)$ & $62(26.1)$ & \multirow{3}{*}{54.0} & \\
\hline Second grade & $26(27.4)$ & $17(27.0)$ & $19(23.8)$ & $62(26.1)$ & & \\
\hline Third grade & $23(24.2)$ & $34(54.0)$ & $57(71.2)$ & $114(47.9)$ & & \\
\hline Secondary level & (29) No\% & (37) $\mathrm{No} \%$ & (61) No\% & (127) $\mathrm{No} \%$ & \multirow{4}{*}{2.1} & \multirow{4}{*}{0.72} \\
\hline First grade & $9(31.0)$ & $9(24.3)$ & $13(21.3)$ & $31(24.4)$ & & \\
\hline Second grades & $8(27.6)$ & $9(24.3)$ & $13(21.3)$ & $30(23.6)$ & & \\
\hline Third grade & $12(41.4)$ & $19(51.4)$ & $35(57.4)$ & $66(52.0)$ & & \\
\hline
\end{tabular}

* Significant. 


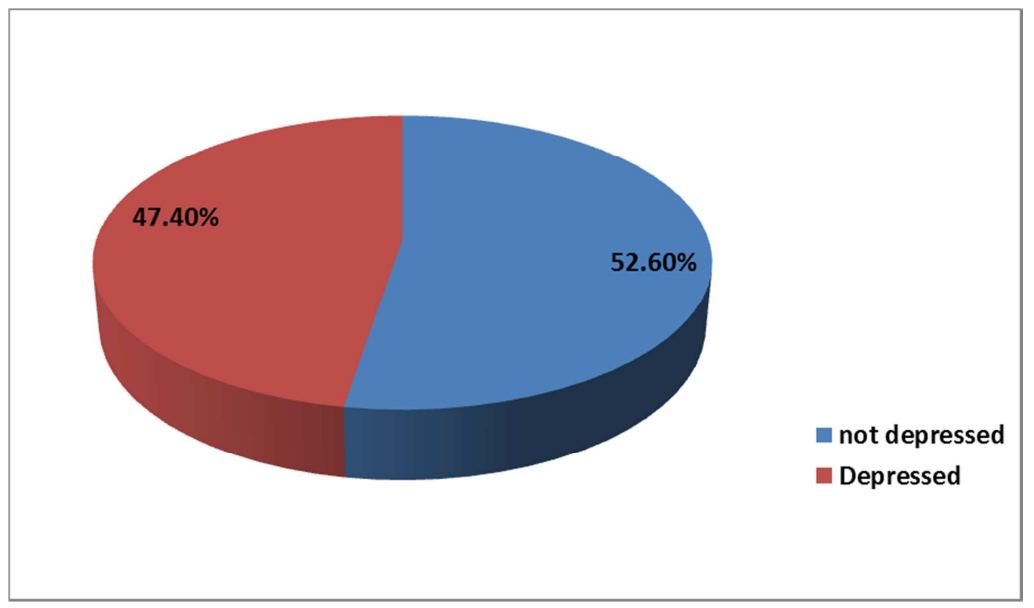

Figure 1. Prevalence of depression among the students according to Moods and Feelings Questionnaire (SMFQ).

Table 4. Crude odds ratio of physically active and moderately active students regarding type of school, education level and grades.

\begin{tabular}{lll}
\hline Variable & $\begin{array}{l}\text { Odds Ratio of physically } \\
\text { active students (95\% CI) }\end{array}$ & $p$ \\
\hline $\begin{array}{l}\text { Type of school } \\
\text { Private }\end{array}$ & $3.7(2.1-6.8)$ & $<0.001^{*}$ \\
Language governmental & $1.2(0.8-2.0)$ & 0.2 \\
Governmental & $0.3(0.2-0.5)$ & $<0.001^{*}$ \\
Education level & & \\
Preparatory & $1.8(1.2-2.8)$ & $0.003^{*}$ \\
Preparatory level & & \\
First & $11(3.8-31.6)$ & $<0.001^{*}$ \\
Second & $1.2(0.6-2.2)$ & 0.3 \\
Third & $0.2(0.1-0.4)$ & $<0.001^{*}$ \\
Secondary level & & 0.2 \\
First & $1.4(0.6-3.1)$ & 0.5 \\
Second & $1.3(0.6-3.0)$ & 0.1 \\
Third & $0.7(0.3-1.3)$ & \\
\hline
\end{tabular}

Crude odds ratio of the secondary outcome presented in table 4: The table shows that physical activity is 3.7 times higher among private schools (95\% CI 2.1-6.8). Also, PA is about 2 times higher among preparatory students (COR 1.8, $95 \%$ CI 1.2-2.8) especially among first grade students $(\mathrm{COR}=11,95 \%$ CI 3.8-31.6) with $\mathrm{P}<0.001$.

Regarding the prevalence of depression in the study sample figure 1 shows that: 173 out of 365 students (47.4\%) are showing symptoms of depression.

Depression is significantly present among insufficiently active students $(53.8 \%) \mathrm{P}=(<0.001)$ and this was the primary outcome. Also, depression was higher among students at governmental schools $(53.2 \%)$ with no statistical significance as seen in table 5. Regarding the difference in presence of depression between preparatory and secondary levels and in between grades there is no statistically significant difference.

Table 5. The relation between presence of depression and physical activity, type of school, education level and grades.

\begin{tabular}{|c|c|c|c|c|c|}
\hline \multirow{3}{*}{ Variable } & \multicolumn{2}{|l|}{ Depression } & \multirow{2}{*}{ Total (365) } & \multirow{3}{*}{$\chi^{2}$} & \multirow{3}{*}{$\mathbf{p}$} \\
\hline & Absent (192) & Present (173) & & & \\
\hline & No $(\%)$ & No (\%) & No (\%) & & \\
\hline \multicolumn{6}{|l|}{ Physical activity } \\
\hline Active & $83(43.2)$ & $41(23.7)$ & $124(34.0)$ & \multirow{3}{*}{32.5} & \multirow{3}{*}{$<0.001 *$} \\
\hline Moderately active & $61(31.8)$ & $39(22.5)$ & $100(27.4)$ & & \\
\hline Insufficiently active (sedentary) & $48(25.0)$ & $93(53.8)$ & $141(38.6)$ & & \\
\hline \multicolumn{6}{|l|}{ Type of school } \\
\hline Private & $56(29.2)$ & 37 (21.4) & $93(25.5)$ & \multirow{4}{*}{3.2} & \multirow{3}{*}{0.21} \\
\hline Language governmental & $48(25.0)$ & $44(25.4)$ & $92(25.2)$ & & \\
\hline Governmental & $88(45.8)$ & $92(53.2)$ & $180(49.3)$ & & \\
\hline \multicolumn{5}{|l|}{ Education Level } & \\
\hline Preparatory & $129(67.2)$ & $109(63.0)$ & $238(65.2)$ & \multirow{4}{*}{0.7} & \multirow{2}{*}{0.20} \\
\hline Secondary & $63(32.8)$ & $64(37.0)$ & $127(34.8)$ & & \\
\hline Preparatory level & (129) No\% & (109) No\% & (238) No\% & & \\
\hline First grade & $39(30.2)$ & $23(21.1)$ & $62(26.1)$ & & \multirow{4}{*}{0.27} \\
\hline Second grade & $33(25.6)$ & $29(26.6)$ & $62(26.1)$ & \multirow[t]{4}{*}{2.7} & \\
\hline Third grade & $57(44.2)$ & $57(52.3)$ & $114(47.8)$ & & \\
\hline Secondary level & (63) $\mathrm{No} \%$ & (64) $\mathrm{No} \%$ & (127) $\mathrm{No} \%$ & & \\
\hline First grade & $17(27.0)$ & $14(21.9)$ & $31(24.4)$ & & \multirow{3}{*}{0.77} \\
\hline Second grade & $15(23.8)$ & $15(23.4)$ & $30(23.6)$ & \multirow[t]{2}{*}{0.5} & \\
\hline Third grade & $31(49.2)$ & $35(54.7)$ & $66(52.0)$ & & \\
\hline
\end{tabular}

* Significant difference. 
In table 6, Depression is significantly higher by 3.9 times among insufficiently active (sedentary) students.

Table 6. Crude odds ratio of depression regarding physical activity, type of school, education level and grades.

\begin{tabular}{lll}
\hline Variable & Odds Ratio of Depressive symptoms (95\% CI) & p \\
\hline Physical activity & Reference & \\
Active & $1.3(0.7-2.2)$ & 0.2 \\
Moderately active & $3.9(2.4-6.5)$ & $<0.001^{*}$ \\
Insufficiently active (sedentary) & & 0.08 \\
Type of school & $1.5(0.9-2.4)$ & 0.6 \\
Private & $0.9(0.6-1.6)$ & 0.08 \\
Language governmental & $0.7(0.5-1.1)$ & 0.2 \\
Governmental & & \\
Education level & $1.20(0.8-1.9)$ & \\
Preparatory & & 0.05 \\
Secondary & & 0.4 \\
Preparatory level & $0.6(0.3-1.1)$ & 0.1 \\
First & $1.0(0.5-1.7)$ & \\
Second & $0.7(0.4-1.2)$ & 0.3 \\
Third & & \\
Secondary level & $1.3(0.6-3.0)$ & 0.5 \\
First & $1.0(0.5-2.3)$ & 0.3 \\
Second & $0.8(0.4-1.6)$ & \\
Third & & \\
\hline
\end{tabular}

There is a significant negative correlation between depression and leisure-time physical activity $(\mathrm{r}=-0.49, \mathrm{P}<0.001)$ seen in table 7 .

Table 7. Correlation between depression and leisure-time physical activity total scores.

\begin{tabular}{lll}
\hline & Depression & \\
\cline { 2 - 3 } & $\mathbf{r}$ & $\boldsymbol{p}$ \\
\hline leisure-time Physical activity & -0.49 & $<0.001 *$ \\
\hline
\end{tabular}

\section{Discussion}

In people aged (10-19) years $16 \%$ of the global burden of disease is due to mental health abnormalities. Half of these conditions start by fourteen years of age and most of them are undetected and untreated. Ignoring mental health conditions in adolescent impair mental and physical health and extend to adulthood. Previous studies postulated that physical activity is associated with a reduction in symptoms of depression in adults, but researches on adolescents are more limited.

Major depression impairs interpersonal relationships and may lead to suicide as it is frequently unrecognized and untreated [10]. Treating depression can be time-consuming and costy so applying new methods to prevent its occurrence in early life is better.

The present study was done on 365 female students with an age range (11-18 years) and a mean age of (14.09 \pm 1.84 SD). Table 1 shows that half of them were attending governmental schools and the other half were in language governmental and private schools. Most of them were in preparatory phase.

World Health Organization (WHO) recommended that (all adolescents should have at least 60 minutes of moderate to vigorous intensity PA daily, which can be developmentally appropriate, enjoyable, and from a variety of activities) [11]. In the present study table 2 shows that: $34.0 \%$ of students were physically active, $27.4 \%$ were moderately active, and about $38.6 \%$ were sedentary.

As seen in tables 3 and 4: The percent of active students are significantly higher among those attending private schools (44.4\%) (COR 3.7, 95\% CI 2.1-6.8) versus (27.4\%$28.2 \%$ ) (COR $1.2,95 \%$ CI $0.8-2.0$ and $0.3,95 \%$ CI $0.2-0.5$ ), respectively in language governmental and in governmental schools with $\mathrm{p}<0.001$, this may be attributed to better family income that allows adolescents to be involved in regular activity sports in social clubs. Also $76.6 \%$ of active students are among preparatory level versus $23.4 \%$ at secondary level (COR 1.8, 95\% CI 1.2-2.8) with ( $\mathrm{p}<0.003$ ). Among preparatory level first grade students are significantly more active (48.4\%) (COR 11.0, 95\% CI 3.8-31.6) than second and third grade of the same level this may be attributed to having more sufficient time for leisure activities than school duties.

The percentage of inactivity was less (better) than that reported by the WHO in 2010: $81 \%$ of school going adolescents aged 11-17 years were insufficiently physically active with higher percentages in the African Region (85\%) [12]. Physical inactivity in this study was also less than that recorded in another study in Brazil on 14-19 years old adolescent students evaluated physical activity using a questionnaire that classified them into those who meet the recommendations and those who do not meet the recommendations. Prevalence of inadequate activity level was $77.2 \%$, with higher levels among older students and those with lower family income [13]. Another study in 2018 
reported that $78 \%$ of the adolescents in secondary school students did not meet the WHO recommendation on physical activity in the last week before the study [14].

Another recent study in 2020 evaluated physical activity among adolescents recorded that $57 \%$ of adolescents were involved in PA up to 3 days/week (95\% CI: 56.9 -57.2). The prevalence of every day PA decreased with age from $28.2 \%$ at (11-12 years) $(95 \% \mathrm{CI}: 27.4-29.0)$ to $21.2 \%$ at $(16-17$ years) (95\% CI: 20.3 -22.0) among boys; and from $19.4 \%$ (95\% CI: $18.5-20.2)$ to $11.1 \%(95 \% \mathrm{CI}: 10.1-12.0)$ in the same ages among girls [15].

Figure 1: shows the prevalence of depression among the studied group was $47.4 \%$. This was close to an Indian study on 1412 students reporting the prevalence of depression to be $49.2 \%$, the overall prevalence was higher among girls $(55.1 \%)$ than boys $(45.8 \%)$ at $(\mathrm{P}<0.001)[16]$. Also close to a study carried out in Taif Area, Kingdom of Saudi Arabia (KSA) on 1024 secondary school female students (15-17 years) recording $42.9 \%$ significant depression assessed by (Beck Depression Inventory) [7]. But the results in this study was higher than two studies done in Cairo, Egypt; one revealed the prevalence of depression in a sample of 602 female adolescents to be $15.3 \%$ (measured by Children Depression Inventory CDI), and $13.3 \%$ (measured by Structured Clinical Interview for DSM-IV Axis I Disorder SCID-I) [17]. The other one recorded the same percentage with the same sample size exactly [18].

Table 5 and 6: shows that depression in this study is significantly present among insufficiently active students (53.8\%) (COR 3.9, 95\% CI 2.4-6.5) with $\mathrm{P}=(<0.001)$. Depression was higher in governmental schools (53.2\%) then language governmental schools (25.4\%) then private schools $(21.4 \%)$ with no statistical significance; this can be attributed to the difference in family income.

Table 7 proves that there is significant negative correlation between depression and leisure-time physical activity ( $\mathrm{r}=$ $0.49, \mathrm{P}<0.001)$.

A previous longitudinal study examined the direction of the association between leisure-time physical activity and depressed mood and found that they are related, but the results did not support the assumption that a higher levels of early physical activity can protect against later depressed mood [19]. Another study evaluated physical activity in adolescents versus depression measured by Mood and Feelings Questionnaire (MFQ) and revealed that students who were more active had a reduced odds of depressive symptoms [OR adj total PA: medium 0.82 (95\% CI: 0.69, 0.97); high 0.69 (95\% CI: 0.57, 0.83)] [20].

A prospective cohort study measured depressive symptoms in adolescents by Short Moods and Feelings Questionnaire (SMFQ) and analyzed the relation between depressive symptoms and physical activity by logistic regression to find that there was a strong evidence for association between them $(\mathrm{P}=0.003)$. Each additional hour of $\mathrm{PA} /$ week was associated with reduced odds of depressive symptoms of about $8 \%$ (girls: $\mathrm{OR}=0.92,95 \%$ CI 0.85 to 1.00 ; boys: $\mathrm{OR}=0.92,95 \%$ CI 0.85 to 0.99 ) [21].
Only one study reported no significant relationship between physical activity and depressive symptoms by the Pearson correlation analysis, among 44 adolescents form Minnesota public high school. Depressive symptoms were evaluated by Reynolds Adolescent Depression Scale (RADS) and PA was calculated with an International Physical Activity Questionnaire (IPAQ), participants recalled how many minutes per day they performed (walking activities, moderate and vigorous activities). Only two participants out of the 44 scored reached the clinical cutoff severity point [22].

\section{Conclusion and Recommendations}

This study supports the few published data that there is an association between depression and physical activity in adolescents, it proves that there is a significant negative correlation between depression and leisure-time physical activity in adolescents but it does not prove that regular physical activity in this age may decrease the incidence of depression in the future and also it is done on only female students, so it is important to do a prospective cohort study on a large scale adolescents of both sexes to prove the association.

As a family physician it's a duty during monitoring the development of adolescents; to direct them to practice physical activity for mental and physical will being and close monitoring of their psychiatric state to early detect depressive disorders that may occur at this age.

\section{References}

[1] World Health Organization. Adolescent mental health. https://www.who.int/news-room/fact-sheets/detail/adolescentmental-health. Accessed August 2020.

[2] Goddings A, Heyes S, Bird G, Viner R, Blakemore S. The relationship between puberty and social emotion processing. Dev Sci 2012; 15 (6): 801-811.

[3] Thapar A, Collishaw S, Pine D, Thapar A. Depression in adolescence. PMC. Lancet 2012; 17: 379 (9820): 1056-1067.

[4] Janssen I, LeBlanc A. Systematic review of the health benefits of physical activity and fitness in school-aged children and youth. The International Journal of Behavioral Nutrition and Physical Activity 2010; 7 (1): 40.

[5] Graham D, Bauer K, Friend S, Barr-Anderson D, NuemarkSztainer D. Personal, behavioral, and socio-environmental correlates of physical activity among adolescent girls: Crosssectional and longitudinal associations. J Phys Act Health 2014; 11 (1): 51-61.

[6] Shennar-Golan V, Walter O. Physical activity intensity among adolescents and association with parent-adolescent relationship and well-being. Am J Mens Health 2018; 12 (5): $1530-1540$.

[7] Desouky DE, Ibrahem RA, Omar MS. Prevalence and comorbidity of depression, anxiety and obsessive compulsive disorders among Saudi secondary school girls, Taif Area, KSA. Arch Iran Med. 2015; 18 (4): 234-238. 
[8] Angold A, Costello E, Messer S, Pickles A, Winder F, Silver D. The development of a short questionnaire for use in epidemiological studies of depression in children and adolescents. International Journal of Methods in Psychiatric Research 1995; 5 (4): 237-249.

[9] Godin G. The Godin-Shephard leisure-time physical activity questionnaire. Health \& Fitness Journal of Canada 2011; 4 (1): $18-22$.

[10] Centers for Disease Control and Prevention. Physical activity for everyone: The benefits of physical activity. http://www.cdc.gov/physicalactivity/everyone/health/index.ht ml. last reviewed: September, 2020.

[11] World Health Organization. Physical activity. Geneva 2018. (Fact Sheet, 385). http://www.who.int/mediacentre/factsheets/fs385/en/ Accessed August 2020.

[12] World Health Organization. Global Health Observatory (GHO) data. Prevalence of insufficient physical activity. https://www.who.int/gho/ncd/risk_factors/physical_activity_te xt/en/. Accessed August 2020.

[13] De Lima TR, Silva DA. Prevalence of physical activity among adolescents in southern Brazil. Journal of Bodywork \& Movement Therapies 2018; (22): 1: 57-63.

[14] Sharma B, Chavez RC, Nam EW. Prevalence and correlates of insufficient physical activity in school adolescents in Peru. Rev Saude Publica 2018; 52: 51.

[15] Marques A, Henriques-Neto D, Peralta M, Martins J, Demetriou Y, Schönbach DM et al. Prevalence of physical activity among adolescents from 105 low, middle, and high- income countries. Int. J. Environ. Res. Public Health 2020; 17: 3145 .

[16] Jha K, Singh SK, Nirala SK, Kumar C, Kumar P, Aggrawal N. Prevalence of depression among school-going adolescents in an urban area of Bihar, India. Indian J Psychol Med 2017; 39 (3): 287-292.

[17] Khalil AH, Rabie MA, Abd-El-Aziz MF, Abdou TA, ElRasheed AH, Sabry WM. Clinical characteristics of depression among adolescent females: a cross-sectional study. Child Adolesc Psychiatry Ment Health. 2010; 4: 26.

[18] El-Missiry A, Soltan M, Abdel Hadi M, Sabry W. Screening for depression in a sample of Egyptian secondary school female students. J Affect Disord 2012; 136 (1-2): e61-e68.

[19] Birkeland MS, Torsheim T, Wold B. A longitudinal study of the relationship between leisure-time physical activity and depressed mood among adolescents. Psychology of Sport and Exercise 2009; 10 (1): 25-34.

[20] Wiles NJ, Haase AM, Lawlor DA, Ness A, Lewis G. Physical activity and depression in adolescents: Cross-sectional findings from the ALSPAC cohort. Soc Psychiatry Psychiatr Epidemiol 2012; 47 (7): 1023-1033.

[21] Rothon C, Edwards P, Bhui K, Viner R, Taylor S, Stansfeld S. Physical activity and depressive symptoms in adolescents: a prospective study. BMC Medicine 2010; 8: 32.

[22] Ganz J. "Relationship between physical activity and depressive symptoms in adolescents" Theses, Dissertations, and Other Capstone Projects 2012. Minnesota State University, Mankato Cornerstone: A Collection of Scholarly and Creative Works for Minnesota State University, Mankato Paper 227. 